\title{
Mechanical Engineering, Materials and Metallography
}

\author{
Iain Le May
}

Metallurgical Consulting Services Ltd.

P.O. Box 5006, Saskatoon, SK S7K 4E3

Canada

I started my professional life as a mechanical engineer, but became involved in the study of the structure and mechanical behaviour of materials during my PhD work which was devoted to materials for steam generation under supercritical conditions. This involved creep behaviour and environmental interactions and included a considerable amount of metallographic examination. Following this, in a faculty position at the University of Saskatchewan, I had responsibility for metallurgical and materials research and teaching in the Mechanical Engineering Department, and the interface between mechanical engineering and materials structure and behaviour has been a continuing area of interest and research.

Both as a professor in a university engineering department and as a professional engineering consultant working on industrial problems, including the analysis of failures often involving legal actions, I have found that the importance of an understanding of the relationships between properties and structure of materials is a key factor and one that, all too often, is not appreciated by many practicing engineers. At the same time, many metallurgists and materials specialists have an inadequate training and knowledge to fully appreciate the mechanical forces and stresses to which components are subjected.

In this paper I intend to describe a few of the cases with which I have been involved in which metallography has been a key component in understanding why failure has taken place or in the evaluation of a component's suitability for service.

The papers that resulted from my use of replica techniques for non-destructive microstructural investigation are among the earliest in this area $[1,2]$. The initial use of the technique came about when I was asked to determine the degree of overheating that had occurred in a $100 \mathrm{MW}$ generator rotor that had been run up to some two-thirds of synchronous speed when the stator windings were accidentally connected to the power grid during testing, following installation of the turbine/generator unit. Large induced electric currents had resulted, and there were heat indications on the outer surface of the rotor, particularly at the ends of cooling slots and at plugs. It was virtually impossible to examine the microstructure directly at the magnifications required because of the curved nature of the surface, so in situ metallographic preparation was followed by the preparation of plastic replicas. The replicas were flattened by mounting them on a cosmetic mirror and examining them in a laboratory metallograph. Today, they would have been gold coated before being examined, but the use of an optical mirror behind the replica was found to provide adequate reflectivity and contrast. My use of replicas has continued and today they are used widely for the evaluation of creep damage, as will be discussed later.

A number of studies that I have made showing the utility of metallographic and fractographic techniques in failure analysis have been published. These studies delineated the failure mechanism 
in a number of railway axle fractures caused by overheating due to loss of lubrication in which liquid lead embrittlement was involved, rather than the more traditionally expected copper embrittlement [3]. The utility of metallographic techniques in solving a complex refinery failure has been demonstrated, this initiating from defective tube manufacture and involving hydrogen leakage and ignition, high temperature rupture, and liquid metal embrittlement by zinc [4]. The case involved an analysis of the growth of a buried crack to the surface during a temperature cycle. This case, together with others involving crack growth, has led to an extensive and ongoing study of the growth of cracks under combined creep and fatigue conditions.

A considerable amount of work has been conducted over the years on the fractography of fatigue fracture and on metallographic and microstructural aspects of fatigue. Although the techniques of estimation of crack growth rate and the stresses involved in this are well documented in the literature, a few cases of interest will be presented, particularly to demonstrate the effect of variable loads and overloads on fatigue crack propagation.

The development of voids and microcracks at elevated temperature under creep conditions has been a focus of the power industry for some years. Various techniques have been developed to measure these effects and to correlate them with the extent of damage and the remaining safe life. However, my co-workers and I have demonstrated conclusively that the estimated damage can be seriously in error in Cr-Mo steels as the apparent voids detected by in situ metallography using replicas or directly may be primarily artefacts created during the polish-etch cycle through extraction of grain boundary carbides [5]. This has shown that commercially used assessment methods such as the Aparameter method, can give very erroneous results [6].

References

[1] M.-W. Lui and I. Le May, The Metallographic Rev. 1 (1972) 30.

[2] M.-W. Lui et al., Praktische Metall. 12 (1975) 319.

[3] I. Le May et al., Mater. Char. 26 (1991) 235.

[4] I. Le May, Pressure Vessel Technology: Theory and Practice, I. Mech. E., London, 2003, 215.

[5] T.L. da Silveira and I. Le May, Mater. Char. 28, 1992, 75.

[6] I. Le May and H.C. Furtado, Int. J. Fracture 97, 1999, 125. 